\title{
Beliefs of Jordanian Children with Thalassemia toward Using Iron Chelation Therapy
}

\author{
Ghada Mohammad Abu Shosha \\ Faculty of Nursing, Child Health Nursing, Zarqa University, Zarqa, Jordan \\ Email: ghada_abushosha@yahoo.com,ghada_abushosha@zu.edu.jo
}

How to cite this paper: Shosha, G.M.A. (2016) Beliefs of Jordanian Children with Thalassemia toward Using Iron Chelation Therapy. Open Journal of Blood Diseases, 6, 23-32.

http://dx.doi.org/10.4236/ojbd.2016.63005

Received: August 4, 2016

Accepted: September 2, 2016

Published: September 5, 2016

Copyright $\odot 2016$ by author and Scientific Research Publishing Inc. This work is licensed under the Creative Commons Attribution International License (CC BY 4.0).

http://creativecommons.org/licenses/by/4.0/

\begin{abstract}
Adherence to thalassemia treatment including chelation drugs is influenced by numerous factors. This study aims to explore beliefs about iron chelation therapy and adherence to this medication in Jordanian children with thalassemia major. In this descriptive cross-sectional study, seventy three patients were selected conveniently to complete the study instruments. Participants reported high adherence to their chelation therapy (88.1\%). The majority (87.6\%) expressed necessity for chelation therapy. However, $42.18 \%$ of the participants expressed their concerns about the therapy in which $57.9 \%$ of them showed concerns about dependency on medicine and $46.4 \%$ of them revealed concerns about the long-term effect of medicine. Overall, about $12.9 \%$ of the participants recorded correct and complete answers about thalassemia and its treatment. Knowledge about thalassemia and concerns about chelation were not significantly associated with adherence to the chelation therapy $(\mathrm{r}=0.32, \mathrm{p}=0.19 ; \mathrm{r}=$ $0.29, \mathrm{p}=0.25$, respectively). However, there was a significant positive relationship between beliefs about the necessity of the therapy and adherence to it $(r=0.38, p=$ 0.03). In conclusion, Jordanian children showed proper adherence to their chelation therapy. Health care professionals should discuss patients' concerns about chelation therapy which might increase patients' adherence to their therapy.
\end{abstract}

\section{Keywords}

Thalassemia, Beliefs, Adherence, Children, Iron Chelation Therapy

\section{Introduction}

Thalassemia is one of the most common genetic blood diseases worldwide. It is characterized by abnormality of hemoglobin production which leads to excessive destruction of erythrocytes. In Jordan, thalassemia carrier rate reached 2\% - 4\% [1]. Consanguineous marriages contribute to increasing the incidences of genetic disorders in Jordan [1]. 
Beta-thalassemia major, the most severe form of thalassemia, is caused by reduced or absent synthesis of the beta globin chains of the hemoglobin. This causes severe anemia and therefore, patients with thalassemia major require regular blood transfusion to sustain life [2] [3]. However, patients with long term blood transfusions develop haemosiderosis resulting in accumulation of iron in the vital organs, organ dysfunction, and death. Further, iron overload includes other complications such as growth retardation and failure of sexual maturation [3]. Consequently, patients require iron chelation therapy to prevent progressive organ failure. The aim of iron chelation therapy is to eliminate excessive iron from blood transfusion with chelators. Chelation therapy should be given regularly in order to work efficiently. This requires strong adherence to the chelation regimen. Deferoxamine (DFO) was the first available chelators for the treatment of iron overload worldwide. Patients with thalassemia major should receive deferoxamine before deposition of iron causes tissue damage. Therefore, treatment with deferoxamine usually started after the first 10 - 20 blood transfusions or when the serum ferritin level increases above $1000 \mu \mathrm{g} / \mathrm{l}$. Deferoxamine is administered by subcutaneous infusion over 8 - 12 hours using portable infusion pump with a minimum of five days per week. Generally, the standard dose is $20-40 \mathrm{mg} / \mathrm{kg}$ for children and about $50-60 \mathrm{mg} / \mathrm{kg}$ for adults [4].

Poor adherence to treatment increases the risk of complications, unnecessary health cost, and morbidity and mortality rates [5] [6]. According to Cao \& Galanello [3] survival of individuals who have been well transfused and treated with appropriate chelation extends beyond the age of 30 years.

Reasons for poor adherence to medication have been studied previously. These factors were classified as non-intentional non-adherence, and intentional non-adherence. Non-intentional non-adherence is usually related to poor memory or understanding [7]. The reasons for intentional non-adherence are connected to problems resulted from medications taking (such as side effects of medications), high cost of medications, and disagreement with the need for treatment or other patient-specific factors [8]. Beliefs about medications are supposed to be associated with intentional non-adherence [9].

According to Horne and Weinman [10], Medication beliefs were found to be more powerful predictors of adherence to treatment than the clinical and sociodemographic variables. In addition, patients' knowledge about their diseases and treatment has shown positive correlation with treatment adherence. Studies found that patients with higher knowledge exhibited more compliance to treatment than insufficient knowledge patients [11]-[13]. Patients' adherence is still a problematic issue in thalassemia treatment [5]. In Jordan, There is a paucity of studies that examined children beliefs and adherence to this therapy. Therefore, this study aimed to assess beliefs, knowledge, and adherence to iron chelation therapy in Jordanian children with thalassemia. In addition, the relationship between these variables was also approached.

\section{Materials and Methods}

A descriptive cross-sectional design was used in this study. A convenience sample of 73 
participants was recruited from three thalassemia treatment clinics in Jordan.

Inclusion criteria were: Jordanian children with thalassemia major between the ages of 8 to 18 years because they had thalassemia for several years and expected to have knowledge about thalassemia and iron chelation therapy, able to communicate with the researcher, have no mental illness, have no other chronic or blood diseases, and should be treated with deferoxamine. Contrary to that, Non-Jordanian patients, patients with altered level of consciousness, and patients with any communication problems were excluded from the study.

\subsection{Instruments}

The study instruments included the following tools:

1) Socio-demographic and disease-related questionnaire which included age, gender, duration and frequency of blood transfusions, duration and frequency of iron chelation therapy.

2) The Beliefs about Medicines Questionnaire (BMQ). This tool was developed to understand people's views about medicines and their adherence to the recommended medication [10]. Its development was to raise evidence that most patients do not take their medicines as prescribed by health care providers [14]. The BMQ scale has been found to correlate with adherence to treatment across many diseases and populations, including cardiac diseases, hypertension, arthritis, HIV and others [6] [15]-[17]. The BMQ comprises two separate scales: The BMQ-Specific scale assesses respondents' beliefs about prescribed medicines that they are currently using for specific conditions. The BMQ-General scale measures respondents' attitudes to medicines in general [18]. The BMQ-Specific has two subscales (necessity and concern) with five questions for each subscale. Answers to all 10 questions were scored on a 5-point Likert scale $(1=$ strongly disagree, 2 = disagree, $3=$ uncertain, $4=$ agree, $5=$ strongly agree) and a total score was calculated. Higher necessity scores indicate higher beliefs in the prescribed medicine and higher concern scores indicated higher levels of concern about treatment [10].

3) Assessment of children knowledge about thalassemia and chelation therapy was measured using a questionnaire consisted of 8 questions. Each item was scored using 0 , 1, 2, 3 ( 0 = no knowledge, $1=$ incorrect, $2=$ correct but incomplete, $3=$ correct and complete). A higher score indicates a higher level of knowledge about thalassemia and chelation therapy. The questionnaire was developed by the researcher based on literature review, and validated by two senior pediatric nurses.

4) The Medication Adherence Report Scale (MARS-5). The MARS-5 was used to assess adherence to the therapy and comprises of 5 common patterns of nonadherent behavior that respondents rated on a 5 -point Likert scale ( $1=$ always, $2=$ often, $3=$ sometimes, $4=$ rarely, $5=$ never). The first statement of the MARS-5 asked participants about unintentional nonadherence, whereas the other four statements asked participants about intentional nonadherence. The total score of this tool ranges from 5 to 25 , in which higher scores indicates higher self-reported adherence [19]-[21]. 


\subsection{Ethical Considerations}

Permissions to conduct this study were obtained from the IRB committee in Zarqa University and thalassemia treatment clinics. Assent form was obtained from the parent of each participant after explaining the purposes of the study. The Assent form contained the purposes of the study, the duration of filling the questionnaires, the rights of participants to withdraw from the study at any time, anonymity and confidentiality issues, and how the results will be disseminated. Participation was entirely voluntary and participants were assured about the anonymity and confidentiality by explaining the process of preserving and presenting the data.

\subsection{Procedure}

A pilot study of 15 Jordanian children with thalassemia was initially conducted. The researcher had met Jordanian children and their parents at thalassemia treatment clinics and explained to them the purposes of the study. Children whose parents agreed to participate in the study and met the eligible criteria filled out the study questionnaires in the presence of the researcher. Participants were encouraged to ask questions and accompanying parents were told not to help their children with answers. The pilot-study patients reported that all questionnaires were clear and easy to understand. Filling out all questionnaires took about 40 - 50 minutes to complete.

\subsection{Data Analysis}

The Statistical Package for Social Sciences software version 18.0. (SPSS 18) program was used. Descriptive statistics included frequencies, percentage, means, standard deviations were used to summarize and describe the distribution of the data. Pearson correlation coefficient was used to examine the relationships between patients' beliefs and adherence to medication, and between patients' knowledge and treatment adherence. The significance level was set at 0.05 .

\section{Results}

A total of 73 Jordanian patients participated in the study. Participants' ages ranged from 8 - 18 years old with a mean of 14.95 years. The majority of participants were females (66\%), while (34\%) were males. All participants were school-aged patients. Almost one third of participants were diagnosed before the age of 9 months (37\%), and about (63\%) were diagnosed at ages between 9 and 12 months. All participants (100\%) were treated with deferoxamine for durations averaged about 5 years. Table 1 illustrates the demographic characteristics of participants.

\subsection{Adherence to Deferoxamine}

Adherence was assessed using the MARS-5. The mean adherence score was 23.14 (SD = 2.12). Most of the participants (88.1\%) were adherent to deferoxamine. About (90.4\%) of participants reported that they rarely or never changed the dosage of their medication. Nearly $(85.7 \%)$ of participants reported that they rarely or never used their medi- 
cation less than prescribed (Table 2).

\subsection{Beliefs about Deferoxamine}

The majority of participants believed that their medication was necessary for maintaining health $(87.6 \%)$. The items scored the highest in the necessity scale were "my health, at present, depends on my medicines" with a mean of 4.82 , followed by "without my medicines I would become very ill" with a mean of 4.39 . On the other hand, $42.18 \%$ of participants had strong concerns about their medication. The highest areas of concerns were reported in "becoming dependent on medicine" with a mean of 4.20, and "the long term effects of medicine" (mean $=3.71$ ). The items that scored the lowest in the concerns scale was "my medicines are a mystery to me" with a mean of 1.36, and "having to take medicines worries me" with a mean of 2.74 (Table 3). The mean of total necessity scores was $21.7(\mathrm{SD}=2.3)$ which was higher than the concerns scores (mean $=15.2, \mathrm{SD}=3.1)$.

Table 1. Demographic characteristics of participants $(N=73)$.

\begin{tabular}{|c|c|}
\hline \multicolumn{2}{|l|}{ Age (years) } \\
\hline Mean (SD), Range & $14.95(4.7), 8-18$ \\
\hline \multicolumn{2}{|l|}{ Gender, N (\%) } \\
\hline Male & $25(34.2 \%)$ \\
\hline Female & $48(65.8 \%)$ \\
\hline \multicolumn{2}{|l|}{ Education level, $\mathrm{N}(\%)$} \\
\hline Elementary & $27(37 \%)$ \\
\hline Preparatory & $36(49.3 \%)$ \\
\hline Secondary & $10(13.7 \%)$ \\
\hline \multicolumn{2}{|c|}{ Age at diagnosis (months), $\mathrm{N}(\%)$} \\
\hline Before 9 months & $27(37 \%)$ \\
\hline $9-12$ months & $46(63 \%)$ \\
\hline \multicolumn{2}{|c|}{ Duration of treatment (years) } \\
\hline Mean (SD) & $5(3.6)$ \\
\hline \multicolumn{2}{|c|}{ Type of chelation therapy, $\mathrm{N}(\%)$} \\
\hline Deferoxamine & $73(100 \%)$ \\
\hline
\end{tabular}

Table 2. Adherence to treatment.

\begin{tabular}{lcc}
\hline \multicolumn{1}{c}{ Items } & Mean (SD) & $\begin{array}{c}\text { Percentage rarely } \\
\text { or never }\end{array}$ \\
\hline & & \\
"I forget to take my medication". & $4.62(0.72)$ & 88.05 \\
"I change the dosage of my medication". & $4.81(0.61)$ & 90.4 \\
"I stop taking my medication for a while". & $4.52(0.73)$ & 87.3 \\
"I decide to skip one of my medication dosages". & $4.74(0.81)$ & 89.1 \\
"I use my medication less than its prescribed". & $4.45(0.56)$ & 85.7 \\
Sum & $23.14(2.12)$ & 88.1 \\
\hline
\end{tabular}


Table 3. Beliefs about medicine.

\begin{tabular}{lcc}
\hline \multicolumn{1}{c}{ Items } & Mean (SD) & $\begin{array}{c}\text { Percentage } \\
\text { agreeing or } \\
\text { strongly } \\
\text { agreeing }\end{array}$ \\
& & \\
Necessity scale & & \\
1. My health, at present, depends on my medicines. & $4.82(0.83)$ & 92.3 \\
2. My life would be impossible without my medicines. & $3.94(0.642)$ & 79.8 \\
3. Without my medicines I would become very ill. & $4.39(0.78)$ & 90.4 \\
4. My health in the future will depend on my medicines. & $4.24(0.56)$ & 86.8 \\
5. My medicines protect me from becoming worse. & $4.31(0.94)$ & 88.7 \\
Sum & $21.7(2.3)$ & 87.6 \\
& & \\
Concerns scale & & 42.1 \\
1. Having to take medicines worries me. & $2.74(1.24)$ & 46.4 \\
2. I sometimes worry about the long-term effects of my medicines. & $3.71(0.96)$ & 23.7 \\
3. My medicines are a mystery to me. & $1.36(0.88)$ & 40.8 \\
4. My medicines disrupt my life. & $3.18(0.64)$ & 57.9 \\
5. I sometimes worry about becoming too dependent on my medicines. & $4.20(1.27)$ & 42.18 \\
Sum & $15.2(3.1)$ & \\
\hline
\end{tabular}

\subsection{Knowledge about Thalassemia}

Regarding knowledge about the disease, only $12.87 \%$ of the participants answered correct answers about thalassemia and its treatment (Table 4). Twenty three percent of the participants gave correct and complete answer about treatment regimen, and about $21 \%$ answered correctly about the side effects of treatment. However, the action of iron chelation therapy scored the lowest percentage (6\%).

\subsection{Associations among Beliefs, Knowledge, and Adherence}

There was no association found between thalassemia knowledge and beliefs to medication (necessity scale, $\mathrm{r}=0.17, \mathrm{p}=0.15$; concerns scale, $\mathrm{r}=-0.06, \mathrm{p}=0.46$ ). Table 4 shows the associations of beliefs about iron chelation therapy with thalassemia knowledge.

Necessity scores correlated significantly with adherence scores $(r=0.38, p=0.03)$. However, concerns scores did not correlate significantly with adherence scores $(r=$ $0.29, \mathrm{p}=0.25)$. In addition, there was no significant correlation between thalassemia knowledge and adherence to medication $(\mathrm{r}=0.32, \mathrm{p}=0.19)$. Table 5 presents the associations of beliefs about iron chelation therapy and thalassemia knowledge with adherence to it.

\section{Discussion}

This study was conducted to examine Jordanian thalassemic children beliefs, knowledge, and adherence about deferoxamine therapy. Jordanian participants reported high adherence to chelation therapy. This high adherence to chelation therapy indicates that patients understand the importance of chelation therapy and the complications associated with not using the therapy. Previous study conducted on thalassemic patients 
Table 4. Knowledge of thalassemia.

\begin{tabular}{cc} 
Items & $\begin{array}{c}\text { Percentage of complete and } \\
\text { correct answers }\end{array}$ \\
\hline Definition of thalassemia & 9 \\
Ways of occurrence & 10 \\
Signs \& symptoms of thalassemia & 12 \\
Complications of the disease & 8 \\
Treatment regimen & 23 \\
Importance of blood transfusion & 14 \\
Action of iron chelation therapy & 6 \\
Side effects of treatment & 21 \\
Sum & 12.87
\end{tabular}

Table 5. Correlation matrix for beliefs in deferoxamine, knowledge about disease and adherence to medication. Pearson correlation coefficient.

\begin{tabular}{ccccc}
\hline & Adherence & Knowledge & BMQ-Necessity & BMQ-Concern \\
\hline Adherence & 1 & & & \\
Knowledge & 0.32 & 1 & 1 & \\
BMQ-Necessity & $0.38^{\star}$ & 0.17 & -0.08 & 1 \\
BMQ-Concern & 0.29 & -0.06 & \\
\hline
\end{tabular}

${ }^{*}$-value $<0.05$.

found similar result [5]. However, this rating was based on self-administered questionnaire and therefore, it depended on participants' recall and they might overestimate their responses toward adherence. Contrary to that, a study conducted by Pedram et al. [22] revealed that thalassemia major patients have poor adherence to deferoxamine whereby adherence was achieved only in 46 patients out of 243 patients (18.2\%) with serum ferritin levels less than $2000 \mu \mathrm{g} / \mathrm{l}$. Pedram et al. [22] in their study measured serum ferritin level to reflect adherence to deferoxamine. Thus, it seems that the using of laboratory investigations such as measuring serum ferritin and liver iron concentration are better methods to examine adherence to chelation therapy than using self-reported questionnaire.

The majority of participants believed in the necessity of their medication. More than one-third of participants reported their strong concerns regarding the long-term effects of medication, dependency on it, and disruption of their lives due to using medication. A previous study conducted by Trachtenberg et al. [5] on patients with thalassemia revealed similar findings. In comparison with other chronic disorder, necessity of iron chelation was higher than that in patients with rheumatoid arthritis and concerns about chelation were lower than those patients with rheumatoid arthritis [6]. 
Regarding patients' knowledge about thalassemia, few patients gave correct and complete answer about the definition of thalassemia. Mostafa \& Elaziz [23] found similar findings whereby $(76 \%)$ of patients were unable to define thalassemia correctly or gave incomplete answer due to the focus of care providers to establish caring and coping with thalassemia more than educating patients. Likewise, only $8 \%$ of participants reported correct answer about the complications of the disease. Mostafa \& Elaziz [23] supported these findings and found that knowledge about disease complications was low because most patients avoid receiving information about the complications of their disease due to distress associated with uncertain future. Contrary to that, giving information about complications associated with thalassemia may encourage patients to comply with health team instructions about care practices and in turns avoid these complications. In similar, only $6 \%$ of participants completely reported the action of iron chelation therapy. This is congruent with the findings of Mostafa \& Elaziz [23] who found that most patients did not know the importance of iron chelation for treating iron overload.

Overall, only about $13 \%$ of participants gave correct and complete answers about thalassemia and iron chelation therapy indicating low level of knowledge among thalassemic patients. Therefore, health care providers are advised to give comprehensive disease-related information for patients in order to deal effectively with their disease.

It is assumed that patients with more knowledge about their disease would have more positive beliefs about the necessity of medication and less concerns related to medication. Surprisingly, there was no association found between thalassemia knowledge and beliefs about the necessity or concerns of medication. Neame and Hammond [6] found similar findings but in patients with rheumatoid arthritis. In addition, the findings of this study revealed no relationship between knowledge of thalassemia and adherence to deferoxamine. In the contrary, Mostafa \& Elaziz [23] found positive association between treatment adherence and patients' knowledge about their disease [23]. Thus, health care provider should not only educate patients about their disease and its treatment, but also listen to their beliefs in the necessity and concerns about medications.

\section{Limitations}

There are some limitations for this study. Firstly, the design of the study is cross-sectional which prevents conclusions about the causality of the studied variables. Secondly, the use of self-administered questionnaire might lead to overestimation of adherence. Finally, filling out the questionnaires was based only on patients' recall which might cause bias in the collected data, and therefore measuring serum ferritin and liver iron concentration are better methods to examine adherence to chelation therapy than using self-reported questionnaire.

\section{Conclusion}

Jordanian children with thalassemia showed proper adherence to deferoxamine. They 
were knowledgeable about the benefits of their medicine. Health care team has to emphasize on the necessity of chelation and address patients' concerns with them. Longitudinal studies are recommended for further studies to examine changes in beliefs and adherence over time. In addition, comparative studies that examine the effects of different types of iron chelation therapies on patients' adherence are recommended.

\section{Conflict of Interest Statement}

The author declares that there is no conflict of interest regarding the publication of this article.

\section{Funding Statement}

"This research is funded by the Deanship of Research and Graduate Studies in Zarqa University/Jordan".

\section{References}

[1] Hamamy, H., Al-Hait, S., Alwan, A. and Ajlouni, K. (2007) Jordan: Communities and Community Genetics. Community Genetics, 10, 52-60. http://dx.doi.org/10.1159/000096282

[2] Ali, S., Sabih, F., Jehan, S., Anwar, M. and Javed, S. (2012) Psychological Distress and Coping Strategies among Parents of Beta-thalassemia Major Patients. International Proceedings of Chemical, Biological and Environmental Engineering, 27, 124-128.

[3] Cao, A. and Galanello, R. (2010) Beta-Thalassemia. Genetics in Medicine, 12, 61-76. http://dx.doi.org/10.1097/GIM.0b013e3181cd68ed

[4] Cappellini, M., Cohen, A., Porter, J., Taher, A. and Viprakasit, V. (2014) Guidelines for the Management of Transfusion Dependent Thalassemia (TDT). 3rd Edition, Thalassemia International Federation (TIF), Cyprus.

[5] Trachtenberg, et al. (2012) Beliefs about Chelation among Thalassemia Patients. Health and Quality of Life Outcomes, 10, 148. http://dx.doi.org/10.1186/1477-7525-10-148

[6] Neame, R. and Hammond, A. (2005) Beliefs about Medications: A Questionnaire Survey of People with Rheumatoid Arthritis. Rheumatology, 44, 762-767. http://dx.doi.org/10.1093/rheumatology/keh587

[7] Bosworth, H.B. (2006) Medication Adherence. In: Bosworth, H.B., Oddone, E.Z., and Weinberger, M., Eds., Patient Treatment Adherence: Concepts, Interventions, and Measurement, Lawrence Erlbaum Associates, Mahwah, NJ, 147-194.

[8] Atkins, L. and Fallowfield, L. (2006) Intentional and Non-Intentional Non-Adherence to Medication amongst Breast Cancer Patients. European Journal of Cancer, 42, 2271-2276. http://dx.doi.org/10.1016/j.ejca.2006.03.004

[9] Porteous, T., Francis, J., Bond, C. and Hannaford, P. (2010) Temporal Stability of Beliefs about Medicines: Implications for Optimizing Adherence. Patient Education and Counseling, 79, 225-230. http://dx.doi.org/10.1016/j.pec.2009.07.037

[10] Horne, R. and Weinman, J. (1999) Patients' Beliefs about Prescribed Medicines and Their Role in Adherence to Treatment in Chronic Physical Illness. Journal of Psychosomatic Research, 47, 555-567. http://dx.doi.org/10.1016/S0022-3999(99)00057-4

[11] Aydinok, Y., Erermis, S., Bukusoglu, N., Yilmaz, D. and Solak U. (2005) Psychosocial Im- 
plications of Thalassemia Major. Pediatrics International, 47, 84-89.

http://dx.doi.org/10.1111/j.1442-200x.2004.02009.x

[12] Kalichman, S.C., Cherry, J. and Cain, D. (2005) Nurse-delivered Antiretroviral Treatment Adherence Intervention for People with Low Literacy Skills and Living with HIV/AIDS. Journal of the Association of Nurses in AIDS, 16, 3-15. http://dx.doi.org/10.1016/j.jana.2005.07.001

[13] Schaffer, S.D. and Tian, L. (2004) Promoting Adherence: Effects of Theory Based Asthma Education. Clinical Nursing Research, 13, 69-89. http://dx.doi.org/10.1177/1054773803259300

[14] McGavock, H. (1996) A Review of the Literature on Drug Adherence. The Royal Pharmaceutical Society of Great Britain and Merck Sharp \& Dohme Ltd., London.

[15] Bane, C., Hughes, C.M. and McElnay, J., C. (2006) The Impact of Depressive Symptoms and Psychosocial Factors on Medication Adherence in Cardiovascular Disease. Patient Education and Counseling, 60, 187-193. http://dx.doi.org/10.1016/j.pec.2005.01.003

[16] Ross, S., Walker, A. and MacLeod, M.J. (2004) Patient Compliance in Hypertension: Role of Illness Perceptions and Treatment Beliefs. Journal of Human Hypertension, 18, 607-613. http://dx.doi.org/10.1038/sj.jhh.1001721

[17] Gauchet, A., Tarquinio, C. and Fischer, G. (2007) Psychosocial Predictors of Medication Adherence among Persons Living with HIV. International Journal of Behavioral Medicine, 14, 141-150. http://dx.doi.org/10.1007/BF03000185

[18] Horne, R., Weinman, J. and Hankins, M. (1999) The Beliefs about Medicines Questionnaire: The Development and Evaluation of a New Method for Assessing the Cognitive Representation of Medication. Psychology and Health, 14, 1-24. http://dx.doi.org/10.1080/08870449908407311

[19] Menckeberg, T.T., Bouvy, M.L., Bracke, M., et al. (2007) A Comparison of Prescription Refill Adherence and Patients' Report to Identify Nonadherence with Inhaled Corticosteroids. Pharmacoepidemiology and Drug Safety, 16, S235-S236.

[20] Jonsdottir, H., Opjordsmoen, S., Birkenaes, A.B., et al. (2010) Medication Adherence in Outpatients with Severe Mental Disorders Relation Between Self-reports and Serum Level. Journal of Clinical Psychopharmacology, 30, 169-175. http://dx.doi.org/10.1097/JCP.0b013e3181d2191e

[21] Mahler, C., Hermann, K., Horne, R., et al. (2010) Assessing Reported Adherence to Pharmacological Treatment Recommendations. Translation and Evaluation of the Medication Adherence Report Scale (MARS) in Germany. Journal of Evaluation in Clinical Practice, 16, 574-579.

[22] Pedram, M., Zandian, K., Keikhaie, B., Akramipour, R., Hashemi, A., Ghahfarokhi, F. and Soudagar, M. (2010) A Report on Chelating Therapy and Patient Compliance by Determination of Serum Ferritin Levels in 243 Thalassemia Major Patients. Iranian Journal of Pediatric Society, 2, 65-69.

[23] Mostafa, S. and Elaziz, M. (2014) Factors Affecting Compliance Plan of Thalassemic Children and Their Mothers in Outpatient Clinic at Zagazig University Hospitals. Journal of Biology, Agriculture and Healthcare, 4, 42-52. 
Submit or recommend next manuscript to SCIRP and we will provide best service for you:

Accepting pre-submission inquiries through Email, Facebook, LinkedIn, Twitter, etc. A wide selection of journals (inclusive of 9 subjects, more than 200 journals)

Providing 24-hour high-quality service

User-friendly online submission system

Fair and swift peer-review system

Efficient typesetting and proofreading procedure

Display of the result of downloads and visits, as well as the number of cited articles

Maximum dissemination of your research work

Submit your manuscript at: http://papersubmission.scirp.org/ 